\title{
LOW-COST ELECTRIC DRYING SYSTEM WITH TEMPERATURE CONTROL FOR PIECES MADE OF PLASTER OF PARIS
}

\author{
JENNY P. VIEDA D. ${ }^{1}$, FERNANDO MARTÍNEZ $S .{ }^{1} \&$ DANTE G. STERPIN B. ${ }^{2}$ \\ ${ }^{1}$ Technology Faculty, Universidad Distrital Francisco José de Caldas, Bogotá, Colombia
}

${ }^{2}$ Electronic Engineering Program, Corporación Unificada Nacional de Educación Superior, Bogotá, Colombia

ABSTRACT
The following paper shows the obtained results of the design and implementation of a low-cost electric
drying system with temperature control, for the elaboration of pieces made of plaster of Paris, in the Bogotá
city, Colombia. In that way, an improvement of the dry time and, thus, the product quality was achieved.
The electric drying system was carried out by a halogen lamp which is the heat source in the oven which
maintains stable the optimal temperature using a proportional controller, for drying the plaster pieces.
Likewise, the sustainability of the project, analyzing the involved costs and the recovery time of the
inversion, was detailed in Colombian pesos (COP).
KEYWORDS: Temperature Proportional Control, Pulse-Width Modulation (PWM), Plaster Pieces Drying

Received: Nov 07, 2020; Accepted: Nov 27, 2020; Published: Dec 5, 2020; Paper Id.: IJMPERDDEC202013

\section{INTRODUCTION}

During the last 10 years, the ambient temperature in Bogotá has ranged from $9^{\circ} \mathrm{C}$ to $20^{\circ} \mathrm{C}$, and the annual average of rainy days has been 214 (TuTiempo.net, 2020). Plaster of Paris, as the main material for the production of ornamental pieces, kneaded with a water ratio of $80 \%$, and left at a constant temperature between $25^{\circ} \mathrm{C}$ and $45^{\circ} \mathrm{C}$ (Rodríguez, 2016), loses almost all of its non-combined water, that is, almost $50 \%$ of its dry weight, in less than 40 minutes. Those conditions affect the drying of pieces made of plaster because they are below the minimum required for the optimal drying, increasing production times by $75 \%$, and causing loss of quality such as fissures in $10 \%$ of the pieces, lack of brightness in $70 \%$, and loss of material in $3 \%$.

In relation to this data, most of the year the temperature is below the ideal temperature to carry out the drying process, so it is essential to develop a drying system that constantly guarantees a temperature of $38^{\circ} \mathrm{C}(\mathrm{Cabrera}$, 1996 \& Zambrano, 2009), because to achieve an optimal product it is necessary to improve the drying process, and reduce its production costs. In this paper, first, the design and results of a temperature control to dry the pieces made of plaster in an oven are presented and, subsequently, the costs of that development are analyzed to calculate the estimated time of recovery of the investment.

\section{METHODOLOGY}

The structure of the oven was built with $15 \mathrm{~mm}$ wood sheets, because it is very stable and easy to work with, supports humidity and is economical. The oven doors are made of glass and its dimensions were obtained based on the possible maximum production capacity of a micro company, and considering the size of the largest piece to be 
elaborated. The measures of the oven are shown in table 1. Three sliding and removable shelves are placed on top of the oven, to hold 20 plaster pieces on each one.

Table 1: Measures of the Ovenas a Plant to Control

\begin{tabular}{|c|c|}
\hline FEATURE & MEASURE [cm.] \\
\hline Height & 78.5 \\
\hline Width & 54.5 \\
\hline Depth & 67 \\
\hline
\end{tabular}

\subsection{Modelling the Plant}

For the initial testing of the plant, the heating system was defined by a halogen lamp with an electrical power of $300 \mathrm{~W}$., a nominal voltage of $120 \mathrm{~V}$. and a current consumption of $2.5 \mathrm{~A}$. This selection was made in order to achieve, inside the oven, similar conditions of a sunny day, to have a fast response time and maximum efficiency for the paint drying process, to improve the brightness of the pieces. The lamp was located in the lower central part of the oven in order to obtain a better temperature distribution. After that, samples of the plant's behaviour were taken in open loop, measuring the voltage by a sensor and the temperature by a thermocouple, using a multimeter, every 10 seconds. The signals are shown in the Figure 1 .
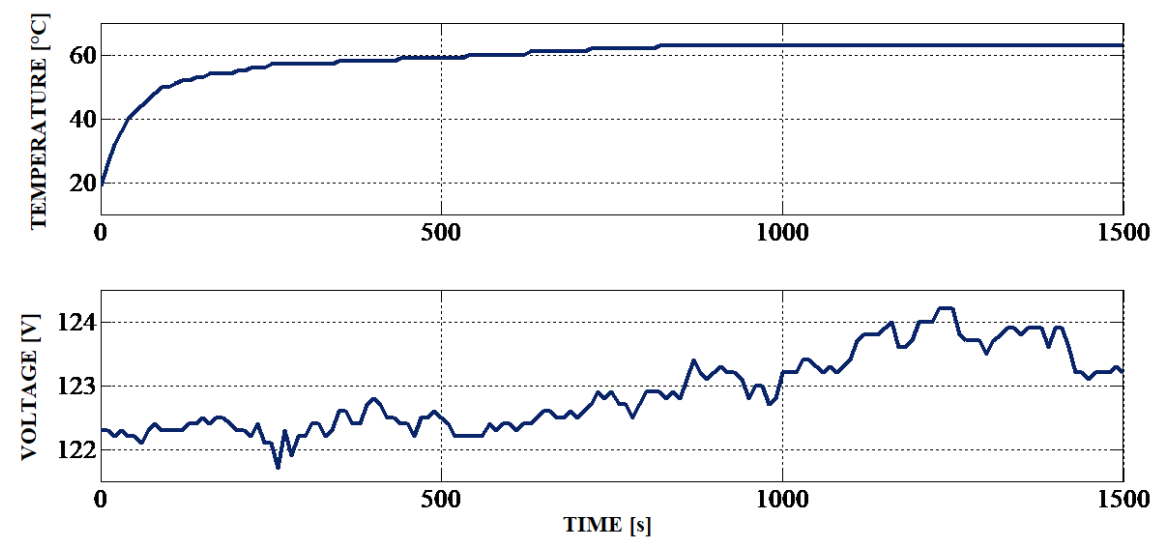

Figure 1: Behaviour of Temperature and Voltage in Open Loop.

These data were imported into Matlab and using the ident tool, the least complex equation was found, with the best approach to plant behavior (Sigmon, 1992, Rairán, 2007 \& MathWorks, 2018). Equation 1 details the mathematical model obtained and Fig. 2 shows the contrast between the real behavior of the plant and its model.

$$
G 1(s)=\frac{k}{(1+T p 1 S)}=\frac{0.51048}{(1+199.41 S)}
$$

\subsection{Getting the Controller}

With the data obtained, the implementation of a PIC16F877A microcontroller was defined (Microchip, 2019; Chekired, F., et al. 2020). Using an algorithm in C language (Gota, D., et al 2020, Nguyen, T., et al. 2018), a proportional controller is made whose output signal will be made in a PWM module that will feed the power stage (dimmer), to control the intensity of the lamp. Figure 3 shows the flow diagram used. 


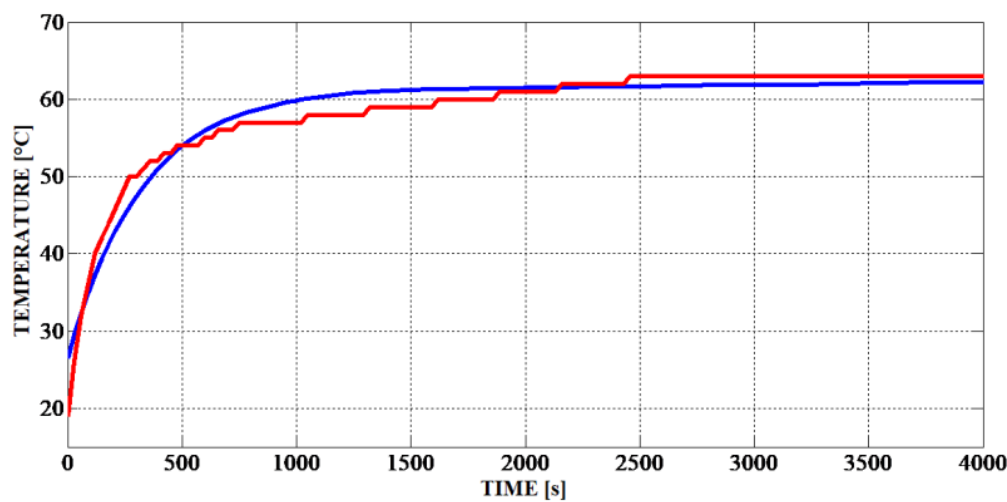

Figure 2: Mathematical Modelling with 72\% of Accuracy.

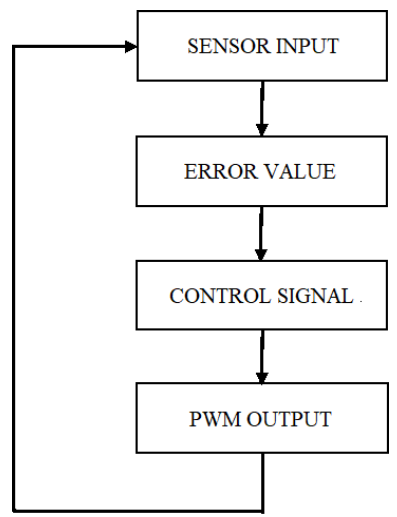

Figure 3: Algorithm for the Controller in the PIC.

\subsubsection{Power Stage}

Since the lamp's power supply is $120 \mathrm{VAC}$ and its current is over $2 \mathrm{~A}$, it is necessary to use a power circuit, and it was done using a dimmer-type circuit. Dimmers are electronic devices capable of regulating the intensity of electrical sources by switching. All dimmer systems operate on the basis of two techniques to limit the current flow in the lamp, which are: i). voltage variation, and ii). Time interval variation, in which the current flows during each of the alternating current cycle.

All thyristor-based dimmer circuits require that the device be triggered at some specific point after the zero crossing of the sine signal. This is done by controlling the driving time of the thyristor, to regulate the current delivered to a load, in order to control the power consumed (Couëdic, 1999). Figure 4 shows the circuit diagram of the power stage used in this work.

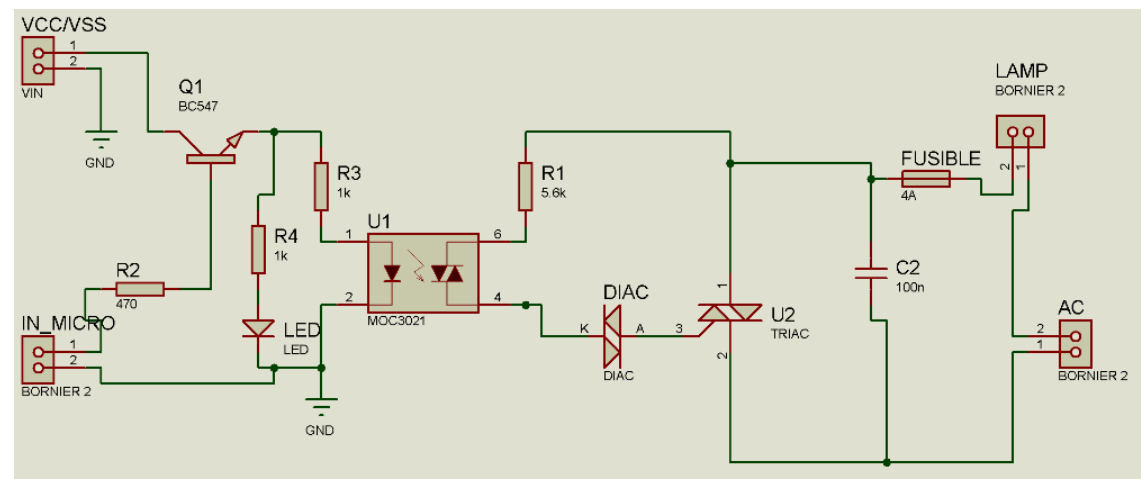

Figure 4: Circuit of the Power Stage. 


\subsubsection{Control Stage}

In the control stage, a proportional controller (Paraskevopoulos, 2017). is used, in which a temperature sampling interval is set every $500 \mathrm{~ms}$, because the sampling frequency is too low and the stability of the system may be degraded, and information may be lost because the signals used change too quickly, and the data present would not be used. Indeed, by defining this sampling time, the amount of information increases and the controller manages to operate quickly and correctly (UPM, 2007).

The output signal is made by a pulse width modulation (PWM) to control the power delivered to the heat source of the temperature control system. The PWM is known as a technique that modifies the duty cycle of a periodic signal (Maloney, 2004). It was determined that using the signal from the temperature sensor, a temperature of $38^{\circ} \mathrm{C}$ was maintained, because the ideal temperature for drying the pieces was established in a range of $35^{\circ} \mathrm{C}$ to $40^{\circ} \mathrm{C}$. An algorithm in $\mathrm{C}$ language was used, and Figure 5 shows the control stage circuit used in this work.

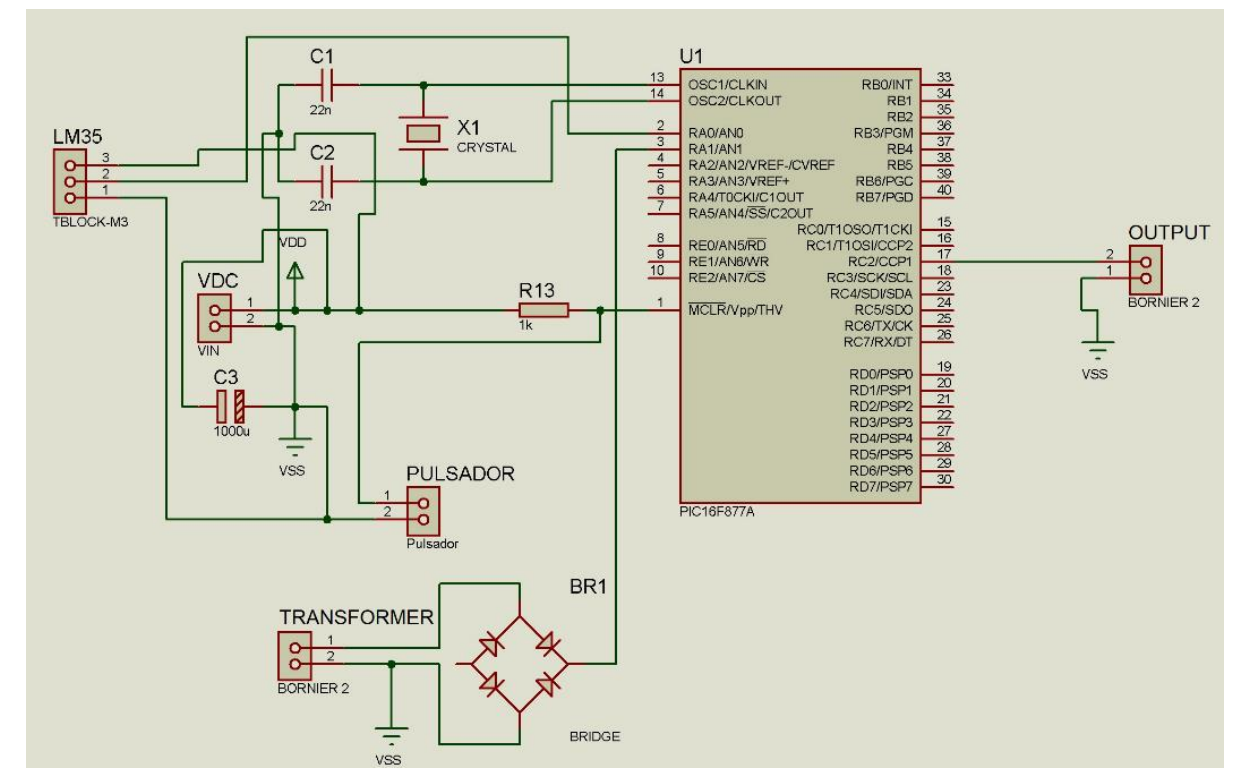

Figure 5: Circuit of the Control Stage.

\subsubsection{Transfer Function}

The implementation of a trigger circuit in the control system implies a disturbance in the transfer function of the plant, so it is necessary to perform the analysis of the behavior and influence of that. The following is the analysis of the response to a 0-10 V ramp stimulus. First the gain behavior of the LM35 sensor is analyzed (Texas Instruments, 1999). When that sensor receives the signal it has a consumption value that is reflected in the transfer function because it is the one that feeds back the signal to the system. Therefore we will call it $\mathrm{H}$ and its gain value is 0.01 . For the direct phase control system is implemented equation 2 that models the firing angle circuits in control systems (Rashid, 2003).

$$
V r m s=V \max \sqrt{\frac{\pi-\alpha}{2 \pi}+\frac{\sin (2 \alpha)}{4 \pi}}
$$

Equation 2 relates the RMS voltage and the firing angle, under ideal conditions, ignoring the voltage drop at the power element and neglecting possible voltage amplitude variations in the power grid. As a result of the implementation of equation 2 we obtain the graph of Figure 6 for the firing angle. From this graph, the linearization area is taken into account 
to obtain the gain value of the trigger angle transfer function that controls the dimmer, and the resulting value is 14.568. With this data, in Figure $7 \mathrm{G} 1$ is the model of the plant, G2 is the gain obtained by the dimmer trigger circuit, and $\mathrm{H}$ is the gain of the sensor.

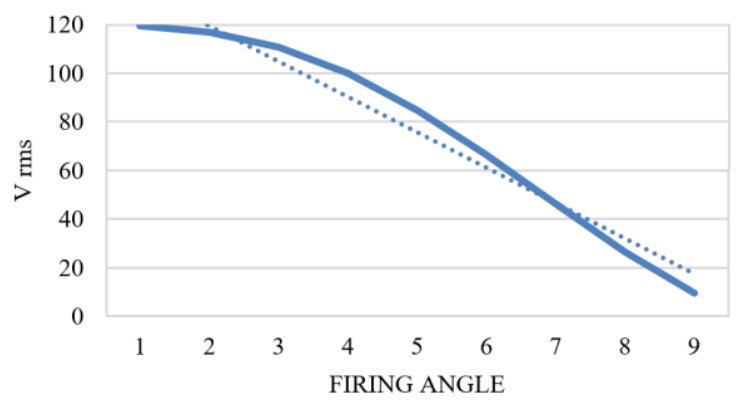

Figure 6: RMS Voltage Applied to the Lamp vs. Firing Angle.

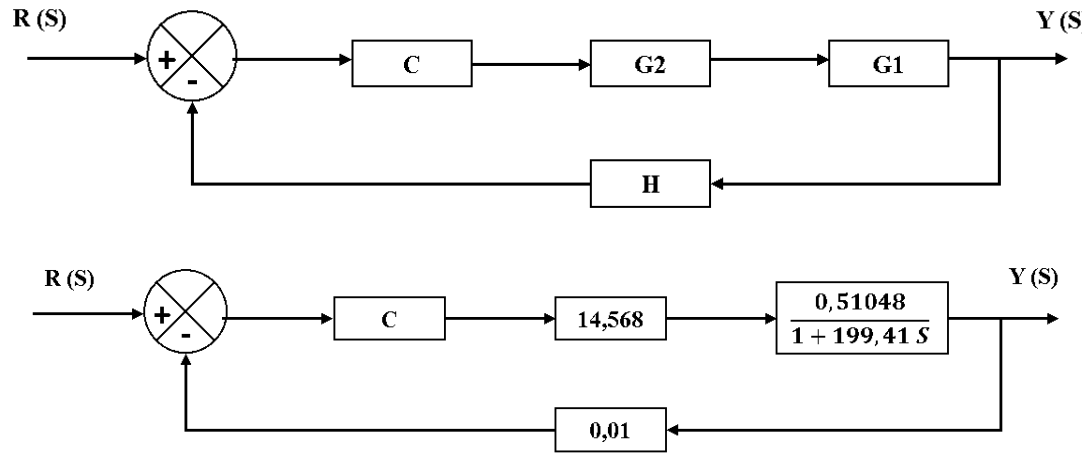

Figure 7: Block diagram with G1, G2 y H.

Solving the block diagram in Figure 7 the transfer function that models the system is obtained, and it is detailed in Figure 8 .

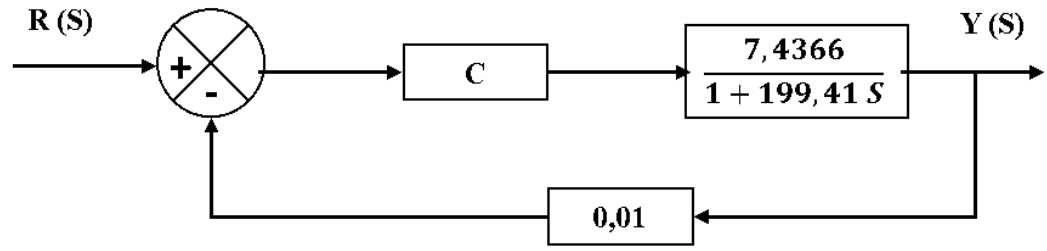

Figure 8: Block diagram Analysed in Matlab.

\subsubsection{Root Locus}

To determine the parameters of the compensator applied to the plant, the compensation by the place of the roots (Dòria-Cerezo, A., \& Bodson, M. 2016; Iqbal, K., 2020) is used, using the matlab's sisotool (MathWorks, 2018). The data of the transfer function $(\mathrm{G})$, the sensor gain $(\mathrm{H})$ and the position of the poles are loaded as it is shown in Figure 8. In consequence, Figure 9 shows the location of the poles and Fig. 10 shows the change of the plant response. The tool optimizes the response of the plant by reducing its stabilization time, and as a result the gain of the compensator $(\mathrm{C}=4)$ is obtained, as finally detailed in Figure 11. 


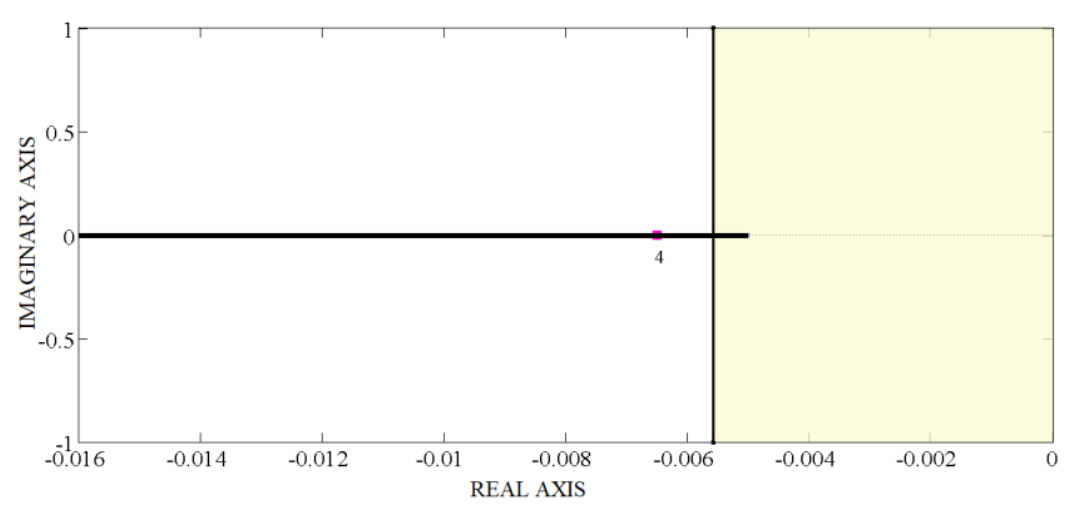

Figure 9: Root Locus Plot.

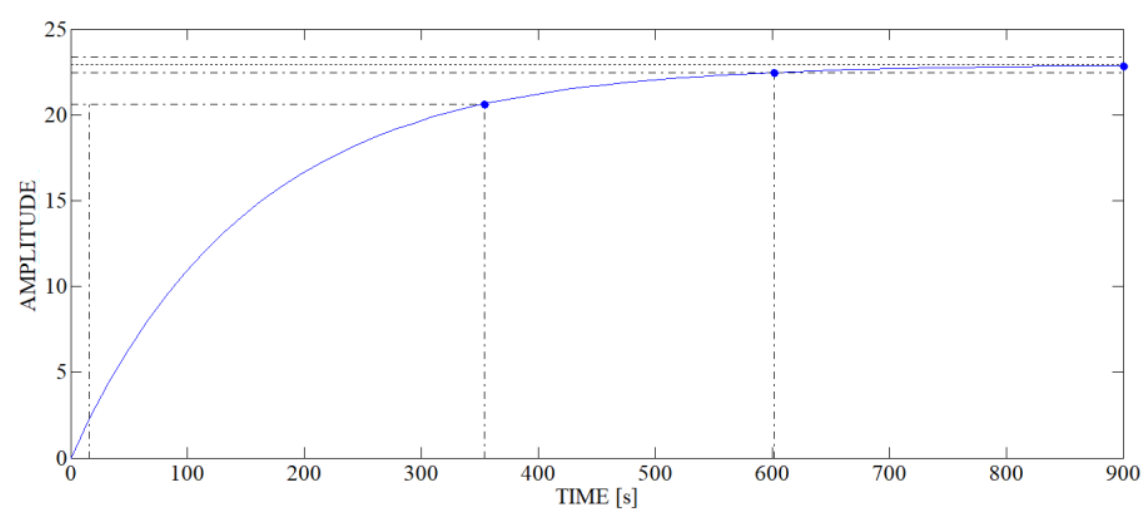

Figure 10: Response of the Plant with Compensation.

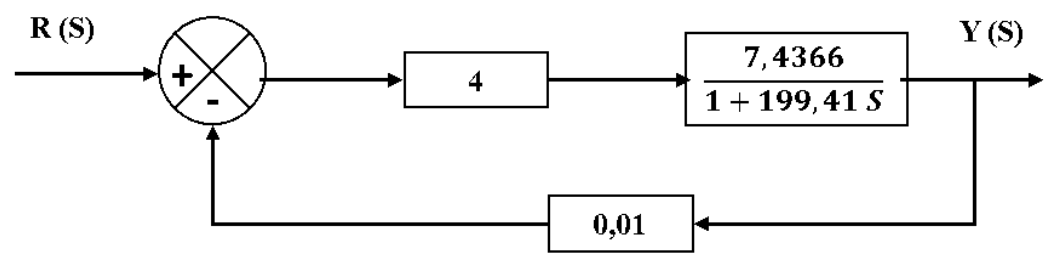

Figure 11: Implemented block diagram.

\subsection{Electric Testing of the System}

With the controller ready, we proceed to perform tests and take measurements in order to know the behavior of the plant when the controller is used. Those measurements were taken with a power quality analyzer DM-III Multitest (Amprobe, 2001), and the obtained results of voltage, current and power, without and with controller are shown in the Figure 12 to 14.
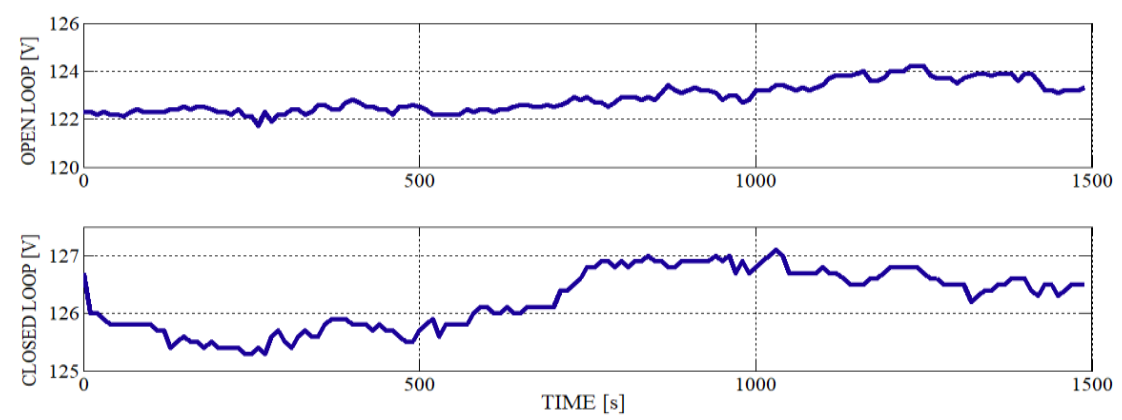

Figure 12: Behaviour of Voltage, without and with Controller. 

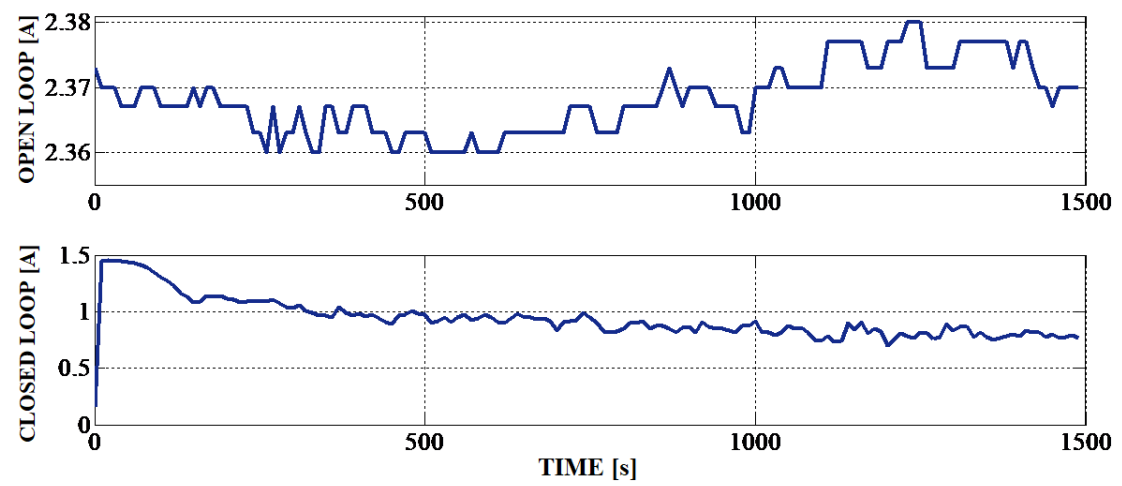

Figure 13: Behaviour of Current, without and with Controller.
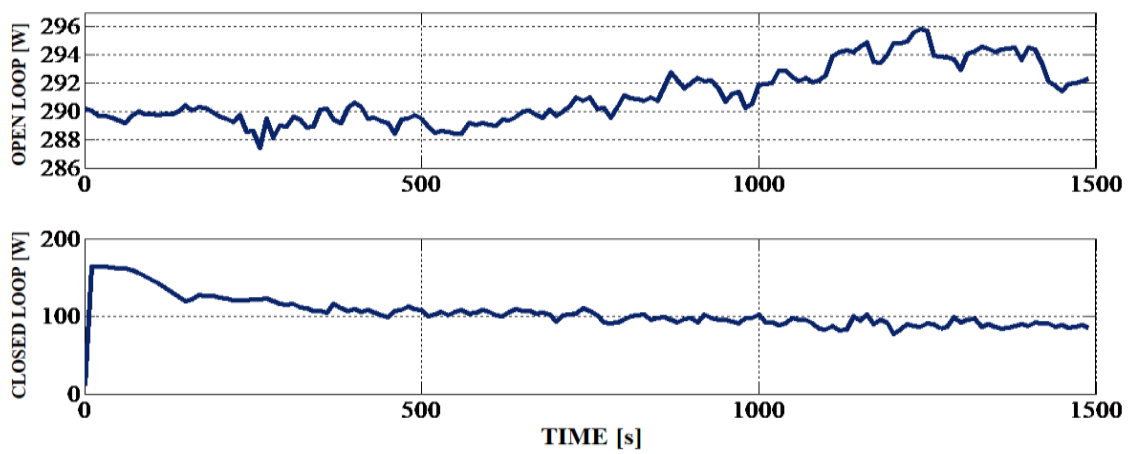

Figure 14: Behaviour of Power, without and with Controller.

Observing the voltage, current and power behaviors, Table 2 details the difference between the plant's consumption without and with a controller. There, we can see that, when using the control system, energy consumption is reduced by $54.8 \%$. Figure 15 shows that when using the oven without temperature control, the temperature increases above $50^{\circ} \mathrm{C}$, which causes compaction problems and the appearance of fissures in the plaster pieces. On the other hand, when using the oven with control, the temperature is stabilized at $38^{\circ} \mathrm{C}$, and under this condition an optimal product is obtained and the drying time is considerably reduced.

Table 2: Averages of the Electrical Measurements

\begin{tabular}{|l|c|c|c|c|}
\hline \multicolumn{1}{|c|}{ Test Condition } & Voltage [V] & Current [A] & Power[W] & Energy[Kw-H] \\
\hline Without controller & 123.12 & 2.37 & 291.82 & 0.27 \\
\hline With controller & 126.40 & 0.84 & 93.75 & 0.08 \\
\hline
\end{tabular}
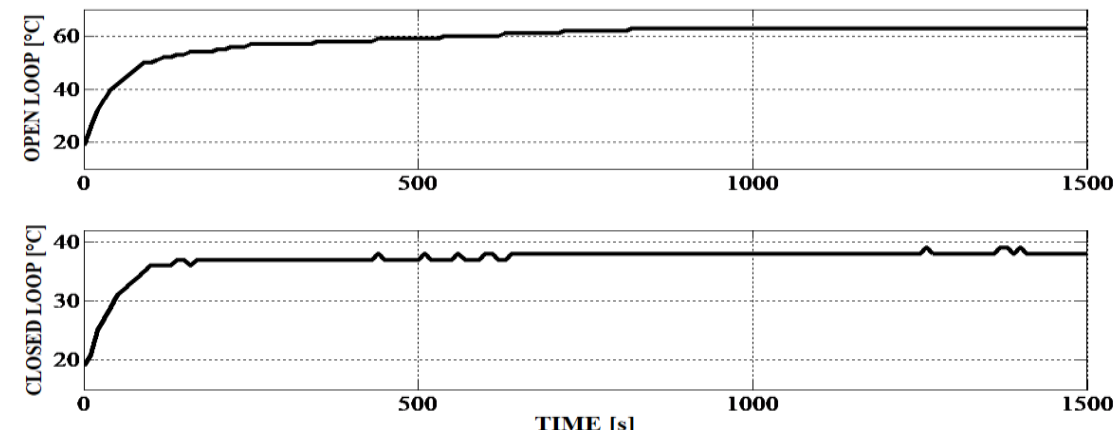

Figure 15: Behaviour of Temperature, without and with Controller. 


\section{RESULTS}

With the plant working at a stable temperature of $38^{\circ} \mathrm{C}$ a batch of the product is taken for testing. The tests in the oven were carried out with half of the batch, i.e. 60 pieces were worked at a constant temperature of $38^{\circ} \mathrm{C}$ inside the oven, while the other half of the pieces were worked at ambient temperature which was ranging from $12^{\circ} \mathrm{C}$ to $20^{\circ} \mathrm{C}$.

During the molding stage of the pieces, those that were worked inside the oven had a drying time of approximately 15 minutes, while in the open air the drying time was 40 minutes. During the casting stage, the drying time inside the oven was 20 hours, with an excellent finish, while for the pieces in the open air, the drying time was 48 hours, with an excellent finish. During the neutralizer drying stage, it was observed that inside the oven it takes 2 minutes, while in the open air it takes 20 minutes. Finally, during the drying of the paint, the time inside the oven was 5 minutes, for each layer of paint, with an excellent finish, while for the pieces in the open air the time was 20 minutes, for each layer of paint, with an approximate temperature of about $16^{\circ} \mathrm{C}$, obtaining a good quality finish but with loss of gloss and a rough surface. These data are consolidated in Table 3.

Table 3: Comparison of Drying Times

\begin{tabular}{|l|l|c|c|}
\hline \multicolumn{2}{|c|}{ Dry Process } & Dry at Open Air [Min.] & Dry in the Oven [Min.] \\
\hline \multirow{2}{*}{ Casting } & Molding & 40 & 15 \\
\cline { 2 - 4 } & Finishing & 2880 & 720 \\
\hline Neutralizer & 10 & 2 \\
\hline Paint (3 layers) & 20 & 5 \\
\hline Total & $2950[2.05$ days] & $742[0.52$ days] \\
\hline
\end{tabular}

\subsection{Costs Analysis and Viability}

With the results obtained, we proceed to calculate the production that can be achieved based on the capacity of the microenterprise, for which we take as statistical data the production in the last three months, that is an average of 180 pieces per week, that is 8640 pieces per year. As the estimated time of production of a piece in the oven is reduced by $75 \%$, the operating capacity of the micro-company was observed and it was noted that the maximum production capacity is 300 pieces per week, which is restrictive because the capacity of the oven is close to 720 pieces, therefore, in table 4 the analysis was made based on a production of 300 pieces per week or 14400 pieces per year.

To determine the value of the profit per piece, the values associated with the production of the piece were studied. Table 5 shows that the cost is $\$ 3,900$, and since the piece is sold at about $\$ 4,700$, the resulting profit value per piece is $\$ 800$. So, for a production without using the oven, the annual profit is $\$ 6,912,000$. Using the oven, the production costs increase by $\$ 113,493$, according to Table 4 , due to the price of the energy consumed annually by the oven. This implies a decrease in the profit per piece of $\$ 8$, but as the production increases to 14400 pieces per year, the final profit is $\$ 11,406,507$ per year.

Table 4: Relation between Production and Profit

\begin{tabular}{|l|c|c|c|c|c|}
\hline \multirow{2}{*}{ Realization } & \multicolumn{3}{|c|}{ Amount of Production } & \multicolumn{2}{c|}{ Profit } \\
\cline { 2 - 6 } & $\begin{array}{c}\text { WEEKLY } \\
\text { [Unit] }\end{array}$ & $\begin{array}{c}\text { MONTHLY } \\
\text { [Unit] }\end{array}$ & $\begin{array}{c}\text { ANNUALY } \\
\text { [Unit] }\end{array}$ & $\begin{array}{c}\text { PER UNIT } \\
\text { [COP] }\end{array}$ & $\begin{array}{c}\text { ANNUAL } \\
\text { [COP] }\end{array}$ \\
\hline Without oven & 180 & 720 & 8640 & $\$ 800$ & $\$ 6,912,000$ \\
\hline With oven & 300 & 1200 & 14400 & $\$ 792$ & $\$ 11,406,507$ \\
\hline
\end{tabular}


Table 5: Production Costs of Each Plaster Piece

\begin{tabular}{|l|c|c|}
\hline \multicolumn{1}{|c|}{ Item } & Without Oven & With Oven \\
\hline Material & $\$ 2,100$ & $\$ 2,100$ \\
\hline Workforce & $\$ 1,800$ & $\$ 1,800$ \\
\hline Energy & $\$ 0$ & $\$ 8$ \\
\hline Total cost & $\$ 3,900$ & $\$ 3,908$ \\
\hline Selling price & $\$ 4,700$ & $\$ 4,700$ \\
\hline Profit & $\$ 800$ & $\$ 792$ \\
\hline
\end{tabular}

\subsection{Return on Investment}

In order to carry out the return on investment (ROI) study (Duermyer, 2020), the value of the total annual profit obtained from the use of the oven is taken, and it is $\$ 11,406,507$. So, the increase in the additional annual profit is calculated, given that the profit is caused by the benefit of using the oven, and it is $\$ 4,548,215$. With this value, the additional daily profit obtained from the use of the oven is $\$ 18,951$, in order to know in how many days the invested in the oven will be recovered, which is $\$ 3,858,635$, the total time required to obtain the ROI is 204 days, as the Table 6 shows. So, the ROI will happen from 9 to 10 months of real working time in the microenterprise.

Table 6: Return on Investment (ROI)

\begin{tabular}{|c|c|c|c|c|}
\hline Profit Increment & Worked Days & Daily Profit & Cost of the Oven & Roi [Days] \\
\hline$\$ 4,548,215$ & 240 & $\$ 18,951$ & $\$ 3,858,635$ & 204 \\
\hline
\end{tabular}

\section{CONCLUSIONS}

In this work a temperature control for a low-cost oven was designed and tested, to improve the quality of pieces made of plaster of Paris, and to increase its profit. So, the drying time of the figures was reduced by $75 \%$. The production of figures was increased by $167 \%$. The return on investment is at most 10 months, and it is expected that the profits in the second year will be $\$ 4$ '548.216. If a control system is not implemented in the oven, the energy consumed will increase by $54.8 \%$. So, the improvement obtained in the quality of the pieces is notorious since it reduces the waste of material and the time of elaboration of the pieces, achieving a better quality in the product. This project is viable, since it generates a better profitability in terms of production, quality and profits, improving the quality of life of the worker, and guaranteeing the timely delivery of the production.

The oven responds adequately in the need to maintain its temperature stable, however the implementation of materials that isolate the internal temperature from the external will improve the ratio of on and off the oven, reducing the cost of operation by energy expenditure. As future work, the efficiency of the oven can be improved by using insulating materials that can maintain the temperature inside for a longer time. It can also be coated on the outside faces for use outdoors, allowing modifications that tend to use other heat sources. Other control methods can be explored to further reduce electrical energy consumption, and a humidity sensor can be added to improve the quality of the pieces, as well as a display to set drying times and visualize the temperature and humidity inside the oven.

\section{ACKNOWLEDGMENTS}

This work was completely supported by the Technology Faculty of Universidad Distrital Francisco José de Caldas. Authors thank ARMOS research group for providing needed equipment and technical support. IDECUN research group, from Corporación Unificada Superior de Educación Superior (CUN), collaborated in the writing of this paper. 


\section{REFERENCES}

1. Amprobe. (2001). DM-III Instruction Manual.

2. Cabrera, R. X. (1996). Diseño y construcción de un prototipo de control de temperatura. Bachelor's thesis, Facultad de Ingeniería Eléctrica, Escuela Politécnica Nacional, Quito, 1996.

3. Couëdic, M. (1999). Circuitos Integrados para Tristores y Triacs. Marcombo.

4. Duermyer, R. (2020). What is Return on Investment or ROI? URL: www.thebalancesmb.com/roi-return-on-investment1794432

5. Maloney, T.J. (2004). Modern Industrial Electronics. 5th edition, Pearson/Prentice-Hall.

6. Microchip Technology Inc. (2019). PIC16F87Xa Data Sheet.https://ww1.microchip.com/downloads/en/devicedoc/39582b.pdf.

7. Chekired, F., Houtti, S., Bouroussis, C. A., Rahmani, A., Tilmatine, A., \& Canale, L. (2020, June). Low Cost Automation System for Smart Houses based on PIC Microcontrollers. In 2020 IEEE International Conference on Environment and Electrical Engineering and 2020 IEEE Industrial and Commercial Power Systems Europe (EEEIC/I\&CPS Europe) (pp. 1-5). IEEE.

8. Gota, D. I., Puscasiu, A., Fanca, A., Miclea, L., \& Valean, H. (2020, May). Smart home automation system using Arduino microcontrollers. In 2020 IEEE International Conference on Automation, Quality and Testing, Robotics (AQTR) (pp. 1-7). IEEE.

9. Nguyen, T., Zoëga Andreasen, S., Wolff, A., \& Duong Bang, D. (2018). From lab on a chip to point of care devices: The role of open source microcontrollers. Micromachines, 9(8), 403.

10. Paraskevopoulos, P. N. (2017). Modern control engineering. CRC Press.

11. Rairán, D. (2007). Análisis de sistemas dinámicos y control PID. Fondo de publicaciones de la Universidad Distrital Francisco José de Caldas, Primera edición, Bogotá, 357.

12. Rashid, M. H. (2003). Power Electronics: Circuits, Devices and Applications. 3rd Edition, Prentice Hall.

13. Rodríguez, M. (2016). Yesos y Escayolas. URL: silo.tips/download/no-title-3740\#

14. Sigmon, K. (1992) MATLAB Primer. Second Edition, Department of Mathematics, University of Florida.

15. Texas Instruments. (1999). LM35 Precision Centigrade Temperature Sensor Data Sheet.

16. Dòria-Cerezo, A., \& Bodson, M. (2016). Design of controllers for electrical power systems using a complex root locus method. IEEE Transactions on Industrial Electronics, 63(6), 3706-3716.

17. Iqbal, K. (2020). 6 Control System Design with Root Locus.

18. The MathWorks Inc. (2018) Control System Toolbox ${ }^{T M}$ User's Guide.

19. TuTiempo.net (2020). Weather Bogota / Eldorado: 1941 - 2020, URL: www.tutiempo.net/clima/ws-802220.html

20. UPM Universidad Politécnica de Madrid. (2007). Sistemas muestreados. Prácticas de Servosistemas, Práctica 10, Departamento de Electrónica, Automática e Informática Industrial, Escuela Universitaria de Ingeniería Técnica Industrial, URL: www.ieef.upm.es/webantigua/spain/Asignaturas/Servos/practicas/prac10_sis_mestr.pdf

21. Zambrano, V. D. (2009). Diseño y construcción de un controlador análogo-digital. Bachelor's thesis, Facultad de Ingeniería Eléctrica y Electrónica, Escuela Politécnica Nacional, Quito, 2009. 